Feature Article

\title{
Challenges to and opportunities for improving mental health services for lesbian, gay, bisexual, and transgender people in Ireland: A narrative account
}

\author{
Edward McCann and Danika Sharek \\ School of Nursing and Midwifery, Trinity College, University of Dublin, Dublin, Ireland
}

\begin{abstract}
The views and opinions of people who use mental health services are being increasingly acknowledged in relation to rights-based, socially-inclusive, and recovery-oriented care. However, little is known of the experiences of lesbian, gay, bisexual, and transgender (LGBT) people in this respect. The aim of the present study was to explore the experiences and needs of LGBT people in relation to mental health services. The study was an exploratory design utilizing mixed methods. Both quantitative and qualitative data were collected using a survey instrument $(\mathrm{n}=125)$ and in-depth semistructured interviews $(\mathrm{n}=20)$ with a sample of people who had completed the survey. This paper will report on the findings from the interview data. The data were thematically analysed, and the main themes that emerged included accessing services, treatment choices, mental health service experiences, and other supports. The findings inform the discussion, and recommendations are made in terms of future mental health practice, education, and research.
\end{abstract}

KEY WORDS: bisexual, gay, lesbian, and transgender people, mental health, nursing, service users.

\section{INTRODUCTION AND BACKGROUND}

Little is known about the experiences and views of lesbian, gay, bisexual, and transgender (LGBT) people in relation to mental health service provision in terms of access and treatment choices. The current study aims to address some of the shortcomings in the literature, and to inform current and future mental health policy and practice initiatives.

Mental health services worldwide have seen major transformations in recent years through deinstitutionalization programmes and more enlightened ways of organizing and providing mental health care, particularly in relation to rights-based, empowering, and service

Correspondence: Edward McCann, Trinity College Dublin, School of Nursing and Midwifery, 24 D'Olier Street, Dublin 2, Ireland. Email: mccanned@tcd.ie

Edward McCann, PhD, RPN, MSc, MA, FHEA.

Danika Sharek, MSc, HDip.

Accepted April 2014. user-led policy initiatives (Australian Government 2010; Department of Health and Children 2006; Government of Scotland 2006; Mental Health Commission 2008). However, in terms of social and emotional well-being, issues still persist for LGBT people. Heterosexism, homophobia, and transphobia can all lead to specific challenges in relation to health equality and social inclusion (Department of Health 2013; Equality Authority 2002; Health Service Executive 2009; World Health Organisation 2009). Furthermore, stigma-related prejudice, discrimination, and heterosexist experiences can have a negative impact upon a person's well-being and might contribute to minority stress (Kelleher 2009; Meyer 1995). In a seminal study conducted in Ireland, Supporting LGBT Lives (Mayock et al. 2009), important issues were highlighted relating to minority stress, including a high incidence of stigma, discrimination, depression, and suicidality, and concerns about social exclusion. In a more recent Irish study involving transgender people 
( $n=153$ ), findings showed that $78 \%$ of transgender people had considered suicide, and a majority of survey respondents reported having negative experiences of health-care services (Transgender Equality Network Ireland 2013). Clearly, these issues require urgent attention in services; however, a significant proportion of respondents in one study (77\%) thought that their healthcare provider lacked knowledge or sensitivity to LGBT issues (Mayock et al. 2009). Furthermore, health and social care systems are often seen as unwelcoming for LGBT people (Coleman et al. 2011; Grant \& Mottet 2011; Pachankis \& Goldfried 2004). For safety and economic reasons, many LGBT people's sexual identities have had to remain hidden, which might lead to further isolation and invisibility (Makadon 2011; Phillips \& Marks 2007). In one US study, a majority of service users in mainstream mental services spoke about feeling compelled to hide their sexual orientation or gender identity, leading to mistrust and the poor uptake of mainstream mental health and social services (Newcomb \& Mustanski 2010). Some of the negative reactions displayed by practitioners might include embarrassment, anxiety, inappropriate reactions, rejection of the patient, hostility, suspicion, pity, condescension, ostracism, avoidance of physical contact, or even refusal of treatment (Heck et al. 2006; McCann et al. 2013). This can have a serious and compounding impact upon a person's mental health (King et al. 2008; Kuyper \& Fokkema 2011). Consequently, accessing appropriate services and the development and sustainability of social networks become problematic for LGBT people (Health Service Executive 2009; Health Service Executive 2012). In spite of these challenges, some studies reveal resilient traits used by LGBT people, and an ability to thrive in perceived heterosexist and transphobic environments (Butler 2004; McNeil et al. 2012; Meyer 2003). Identified strengths that LGBT people might possess include enhanced coping skills, acceptance of diversity, creation of families of choice, and flexibility in gender roles. In terms of resilient traits specific to transgender individuals, more than $80 \%$ of participants in a UK study felt that they had gained something positive as a result of being transgender, transitioning, or expressing their gender identity. These included increased confidence, new friends, betterquality relationships, a sense of community and belonging, enhanced self-expression and acceptance, increased knowledge and insight, and increased happiness and contentment (McNeil et al. 2012). Despite these positive attributes, obstacles persist in terms of discrimination, stigma, and heterosexist attitudes towards LGBT people. Nevertheless, there is a distinct lack of studies that explicitly explores the views of LGBT people in relation to mental health need and service provision. This is particularly evident where transgender people are concerned (Collins \& Sheehan 2004; Grant \& Mottet 2011). In the recent Burning Issues report in Ireland that sought the views of LGBT people around current LGBT priorities $(n=1127)$, mental health concerns came top of the agenda for a majority of people (National Gay and Lesbian Federation 2009). This paper presents the findings from the current study that highlights the views and opinions of LGBT people in relation to mental health services.

\section{METHODS}

\section{Aim and objectives}

The aim of the study was to examine the experiences of LGBT people concerning mental health services in Ireland. The objectives included uncovering positive and negative experiences; identifying potential barriers, opportunities, and gaps within mental health service; and highlighting evidence of good practice that might inform future mental health policy directives.

\section{Design}

The study was an exploratory design utilizing mixed methods. Both quantitative and qualitative data were collected using a survey instrument $(n=125)$ and semistructured interviews $(n=20)$ with a sample of people who had completed the survey. This paper will report on the findings from the interview data. The survey results are reported elsewhere (McCann \& Sharek 2013).

\section{Recruitment and interviews}

The existing literature revealed challenges faced by researchers conducting sensitive research among hard-toreach populations, and recognizes the invisibility and marginalization of LGBT identities in society (Grossman \& Hollibaugh 2008; Shankle et al. 2003). Therefore, a rigorous recruitment strategy was adopted in order to promote the study. LGBT and mental health organizations, including hospitals and clinics $(n=170)$, throughout the country were sent study information. Relevant LGBT and mental health organizations were sent emails requesting that they share the study information through their email lists and social media pages. Following completion of the online survey, respondents were informed of the option to participate in an interview about their experiences. If they were interested, they were asked to fill in the interest form online or to contact the researcher by email or phone. The principal investigator and the 
advisory group developed the semistructured interview guide. The schedule was piloted, and alterations were made. Finally, interviews were conducted with a number of participants who had completed the online survey $(n=20)$ and had elected to participate. All interviews were tape recorded and lasted between $45 \mathrm{~min}$ and 1 hour. The data were collected in 2011 over a 3-month period.

\section{Inclusion criteria and sampling}

People could participate in the study if they were over 18 years of age, identified as LGBT, and had used Irish mental health services in the past 5 years. In order to increase the response rate in hidden or hard-to-reach populations, a convenience sampling strategy was used (Flanagan \& Hancock 2010).

\section{Ethical approval}

The study was reviewed, and ethical approval to conduct the study was granted by the relevant research ethics committee. Further, due to the sensitive nature of the research, LGBT research guidelines were utilized (Kandirikirira \& Botfield 2004). Throughout the interview process, the researcher was aware of, and acknowledged the sensitive nature of, potential discussions. Verbal information was given to participants, and they were encouraged to ask questions at any time. Interview participants were also informed of their right to stop the interview at any time without consequence. When a few of the participants became emotional during the interviews, the researcher was able to offer supportive counselling. A list of national mental health organizations and helplines were also provided to each participant in case they wished to speak to anyone further. All participants signed an informed consent form. All study files, including audio-recordings, transcripts, and surveys, were stored in accordance with the Data Protection (Amendment) Act 2003 (Government of Ireland 2003).

\section{Participant profiles}

In total, 20 people participated in the semistructured interviews. The mean age of the participants was 34.1 years. All of the participants were under 65 years of age, and there was an even distribution in the 18-64-year age brackets. Approximately $75 \%$ were from Ireland, with $80 \%$ living in an urban location. Eighty percent of the sample were working or were students, and $15 \%$ were unable to work due to permanent sickness or disability. A majority of participants were single $(70 \%)$, with smaller percentages dating or in a relationship. In terms of sexual orientation, $45 \%$ of the participants identified as gay, $45 \%$ as lesbian, and one person as bisexual. Forty percent of participants described their gender identity as male, $45 \%$ as female, and $15 \%$ as transgender.

\section{Data analysis}

An independent person transcribed the interview data verbatim. Transcripts were reviewed, and any identifying information removed by the principal investigator. The computer programme, NVivo version 8.0, was used to assist in the organization and analyses of interview data (QSR International 2008). The first two interviews were open coded, and a coding guide was developed that was used to analyse the remaining transcripts for new concepts or emergent themes. The data were further examined for meaning, and similar themes were combined. This constant comparative process continued until major categories were formulated. A synthesis stage followed, where the interview findings were reviewed (Lincoln \& Guba 1985).

\section{STUDY RESULTS}

Categories and subcategories emerged that were organized systematically. The key categories included accessing services, treatment choices, service experiences, other supports, and main concerns and recommendations.

\section{Accessing services}

People had a variety of reasons for seeking out mental health services, and conveyed diverse experiences. The first contact usually involved a consultation with the person's general practitioner (GP). The student counselling service would see people at university or college, and referrals would then be made to mental health services. The following excerpts highlight preliminary expectations and the needs of some of the participants:

I used the college services, actually, because they were free access, and that was a major thing, because I can't afford to actually go to other services, even though I did have a medical card, there's a long waiting list ... so I made use of the GP services who (sic) referred me then to the mental health services. (Lesbian 001)

My dad died ... and I took it pretty bad, and then I was raped. I took an overdose. I was in the general hospital for 3 weeks, and then transferred to the psychiatric hospital for 3 months. Can't remember much; I was sedated a lot of the time. (Lesbian 009)

Several people were able to give very poignant accounts of how their mental health experiences impacted upon them emotionally: 
Agony . . . I'd never ever attempt suicide. I wanted something else to happen. I wanted to get cancer. I wanted to get hit by a car. I wanted the mental pain to be taken off my hands. (Gay 014)

My mum brought me to a priest, hoping that he'd fix me. ... I know from an early age I used to suffer from depression. Actually, it got so bad that I was admitted to the psychiatric hospital. I was suicidal and mentally exhausted, and totally lost and confused. (Gay 016 Gay)

One participant, who had been diagnosed with HIV/ AIDS and had been living in London, returned to rural Ireland, where he had spent his formative years. He was referred to mental health services and had spent over 1 hour being assessed by a consultant:

I was lying on her (consultant) bench one afternoon sobbing, but she never so much as asked me, 'How are you?', and that is a really serious issue for people with HIV. If she'd asked me how I was, I'd have said, 'I need help', but I wasn't able to ask for help because I was in such a depressed state. (Gay 012)

The services to transgender people remain extremely limited, and the frustrations related to accessing appropriate services became increasingly apparent for some participants:

I was seeing another psychiatrist in London, having tried to get the hospital to provide the signature to go for the HSE's (Ireland's National Health Service) treatment fund. It's an enormously long process. . . . I'd even contemplated suicide. (Transgender female 006)

Despite evident setbacks, some transgender people were able to express feelings of positivity and demonstrate resilience:

The one thing that he did say, I'll never forget it, 'You've such hope'. I just thought I was something to be ashamed of, something to be embarrassed over, whereas that sentence just ... made me feel like a human being. (Transgender female 008)

She returned from her consultation with the psychologist and decided to explain to her partner of 14 years, the mother of her two children:

As much as she knew I was trans, she certainly didn't think I would go the whole way with it. . . . The relationship went downhill from there. (Transgender female 008)

The situation had reached breaking point, and while she was coming to terms with her own life and the gender identity disorder diagnosis, she felt the relationship was in jeopardy and feared for the well-being of her family and herself:
It was absolutely awful . . . it wasn't the sexual orientation. She (partner) was my best friend, we were just so close, we never went anywhere without each other, but the fear of everyone else was just something that she couldn't do ... there was no counsellor, there was no support. I totally contemplated suicide, and the faces of my two children kept me alive. (Transgender female 008)

\section{Being diagnosed and being LGBT}

Being an LGBT person in Ireland has specific challenges, especially around minority stress and its manifestations. Participants spoke about the impact of psychiatric diagnoses, and whether or not the person's mental health issues were closely linked with being LGBT:

Borderline personality disorder, they said. It meant nothing to me until I went home and researched it on the internet. ... There's nothing wrong with my personality. I spoke to (a Catholic volunteering organization) to talk it through and they considered it (my sexual orientation) sinful. (Lesbian 009)

Because I kind of have had that experience, like when they ask about your sexuality, like it's tied up with some kind of theory that it's linked with your mental health. Like if someone said they were heterosexual, I don't think it would even be written down, 'Ooh, gay, troubled'. (Lesbian 017)

\section{Treatment choices}

\section{Medication}

Most of the participants had been prescribed medication at some point, and all but one had concerns about taking the medication. The two participants below described fears about developing an addiction to medication and of not being listened to by their doctor:

I was slipping further and further. I went down to my GP and he put me on Valium and sleeping tablets and ... I mean, it was great for a short-term fix, obviously. I'm still on Diazepam, but I only take it when I need it, because I'm not developing an addiction to Diazepam. (Gay 014)

He kept upping it . . . they (the doctor) are not really for receiving feedback about what your opinion is. (Gay 005)

Other participants echoed these fears, while others voiced concerns about increased anxiety about sexual dysfunctions related to psychotropic medications.

\section{Talking therapies}

Some people had experienced different forms of therapy, namely cognitive behavioural therapy, mindfulness, and psychoanalysis. People generally had positive reactions to therapy, but appreciated the challenges of finding the 
'right' therapist. However, there were financial costs involved, and only open to those who could afford it:

My counsellor referred me to a mindfulness group run by a psychiatric nurse. . . 300 Euros ... The mindfulness group helped me to be able to forgive. Living like that is good. Making time for myself. It is good value, and it works! (Lesbian 019)

\section{Service experiences}

Engaging with practitioners and services

In the present study, the desired qualities and attitudes for a good practitioner were identified and articulated by some of the interviewees. Qualities that participants spoke about appreciating were feeling listened to and that their needs and wants were taken into consideration.

My GP, she takes the holistic approach. It's like we're going to look at the bigger picture, and I think that was important, because one of my big fears was that I'd end up in the mental hospital. (Gay 003)

One participant, who had had a negative experience of general medicine where there was poor communication about his condition, felt ambivalent about the treatment he would receive from mental health services:

You see that having been my experience with the health services, it was just like would mental health be the same, but I was thankful that it was very supportive, very understanding, they really did understand. The talking was the important thing. ... They did check to see that you understood what they were saying. (Gay 003)

Others commented on the positive input they had received from various mental health practitioners:

When you're in one-to-one counselling, before you actually mentioned your sexuality, you feel fear of rejection, and it's after ... say, your girlfriend or whatever and ... they're positive, that you feel more comfortable to talk. I was lucky to get somebody who was understanding and compassionate. (Lesbian 001)

Some participants were appreciative of the empowering nature of services that had input and the involvement from service users:

It was service user run. We were put in charge basically. We volunteered. We had meetings where all the decisions were made, our budget, but at the same time, we had a huge input into that, which I think was good; it was reminding us that we were still in control. (Gay 003)

The obverse of the more positive attitudes alluded to by participants included health-care practitioners ignoring or making presumptions about a person's LGBT identity, judging the client, or offering inappropriate treatment. The importance of attributes, such as being treated with respect and dignity, is demonstrated in the following quotes:

I didn't like their attitude . . . assumed that I liked to play football and all this ... . it was a bit odd ... made me feel strange, that was one of the things. I was asked by one of the counsellors if I ever had a relationship with a girl ... I've never had a girlfriend, it was just so awkward. (Gay 010)

He (psychiatrist) was talking about me like I wasn't there in the room. That was horrible, and he was sitting there and he was talking to my dad as if . . it was like being a dog at the vet ... it was like being completely objectified. (Gay 014)

I'd like to see them give a little bit more time and a bit more compassion. (Lesbian 002)

\section{Lack of treatment choices}

The dominance of the biomedical approach within mental health services in Ireland was apparent for some people. Furthermore, a significant proportion of participants had major concerns about the distinct lack of therapeutic choices or appropriate care environments:

I remember looking at the place thinking 'Dear god almighty'. It was like something out of One Flew over the Cuckoo's Nest. It really was horrendous. You could imagine Nurse Ratchett walking down that ward and being horribly cruel to everybody, not a very good memory of what mental health services should be, just wasn't positive. (Lesbian 007)

In 20 years of using the services, the HIV services, the best medical services; however, we have the worst mental health-care system in the world. We don't even have a mental health-care system. HIV and mental health are not linked service wise at all. (Gay 012)

\section{Being LGBT and service provision}

Participants were asked if being LGBT affected the kind of services they received or how they responded within mental health services. For some people, the attitudes of practitioners were important:

Unless you're aggressive, which might be seen as more heteronormative, heterosexual, or whatever ... they might not respect you as much and they're not as likely to listen. You're trusting them with your health and they spit it back in your face ... and if they dose you up enough, you'll be quiet, like a good little puppy. (Gay 014) 
Other people spoke of fears related to being admitted to the psychiatric hospital and potential institutionalization:

You're only allowed one visitor, it's just because ... it's scary, and if you're in there, it's because, unfortunately, there's nowhere else, that was my biggest fear . . . that I would be there forever. (Gay 003)

People were asked how comfortable they were about revealing their LGBT identity and the kind of reaction they received from service providers:

I had a team meeting ... I think it was on the Monday that I had already talked to my social worker about my being gay. I was brought into the team meeting and my consultant brought up about me being gay ... I asked to leave the room because I felt so uncomfortable. (Gay 010)

One participant, while attending a therapy group, found it difficult to divulge her sexual orientation and recalled painful memories:

I didn't tell them because there was a little voice inside of me that reminded me of school. I was outed to the entire school by a girl. I went back after Christmas, and like, the entire school were asking if I regretted it. You just want to curl up into a foetal position and rock backwards and forwards and go 'Oh my god, go away', and use the invisibility cloak that they have in Harry Potter. (Lesbian 002)

\section{Stigma and discrimination}

Mental health media campaigns in Ireland, and work being carried out in LGBT groups in the non-statutory sector on raising awareness, might be positively affecting societal attitudes toward LGBT people. However, a significant number of people in the study mentioned stigma and discrimination and the perceived challenges that still exist for LGBT people. Some of the key issues are highlighted in the following excerpts:

There's a stigma about being gay, especially with the older generation. My generation, it's kind of okay, but if you're rural based, there's still a massive stigma. It could be hard to access services, if they exist at all. (Gay 003)

I feel absolutely let down. They (practitioners) don't think we have a voice, or that we're too weak to complain or no one will listen to us because 'they're crazy'. They're using the stigma ... to think that those people will be quiet, they'll sit there quietly in the corner and take what they're given. There is a lot of shame there. You can feel it in that room. (Gay 014)

Apart from sexual and gender identity issues, some of the participants spoke of the additional stressors related to 'not being Irish' or 'white' and the negative societal consequences. One woman articulated her concerns:

Discrimination doesn't really happen just because you're lesbian. I mean, you probably mightn't get a job because you're a lesbian. You mightn't get to the top of the ladder because you're a lesbian, but I think when there are other areas of discrimination going on, it's really hard, it gets mixed up sometimes. You're not sure. Is it because you're lesbian? Because you're working class? Because you might be disabled? You might be black . . . and that gets mixed up. (Lesbian 011)

Giving consideration to tackling discrimination, several people recognized national campaigns being run, primarily by non-governmental organizations, and the importance of changing attitudes:

Take Care of your Mental Health campaign (a mental health antistigma campaign). It was actually done quite well. Someone might have it, but you don't treat them any differently. (Gay 004)

You can have all the legislation in the whole wide world, but if your attitude hasn't changed, then that legislation is absolutely useless, because the enforcers have the attitudes, so where do you go with that? (Lesbian 011)

\section{Other supports}

Intimate relationships

In terms of intimate relationships and coping with the other person's experiences of mental distress, the strain on the partnership was evident for some of the participants:

My partner asked to come and see me. Like, I'd already told him I wanted to end it all. I don't think he really realized how bad I can get, and I just knew I was heading for a breakdown, and I didn't want him to see me this way. (Gay 010)

That relationship broke down and that's one of the reasons I went off the rails, kind of like because while I had the friends to support me, he was in a way, trying to be, but he didn't know how to deal with it. (Gay 003)

Some participants recognized the importance of the support that they received from their partners in terms of openness, understanding, and making sense of the person's experience:

It's healthy, like we're very honest with each other ... with my depression, I talked to my partner about it, and he was actually really supportive at the time; he's like my counsellor. (Gay 004) 


\section{Supportive family and friends}

Many of the participants spoke of feeling supported by family and friends, and how this was influential in the person's recovery trajectory:

I try to see it as something that anyone can go through, and so we should be able to talk about it. I am really lucky with my friends; they really rallied around me and supported me, and my family as well, and I was extremely lucky there was always someone looking out for me. (Gay 003)

However, for some participants, family members displayed negative emotional responses to the person's sexuality, and this appeared to compound issues that might be related to minority stress:

My grandmother's view on it ... she told me that I needed to be fixed. She's the only person who has ever made me feel that there was something wrong with me, and at the same time, I knew there wasn't anything wrong, but she knows how to push my buttons. (Gay 004)

Well, my father has a very poor attitude ... (he believes that you should) deal with your problems without a psychiatrist. ... deal with your problems yourself forms you as a person. (Gay 005)

\section{Social support groups}

One person alluded to a service provided by the nonstatutory sector and run along the lines of a therapeutic community. There is a sense of shared understanding and mutuality of support to one another:

The various support groups that Schizophrenia Ireland ran, we had great input in how it was going to be run and everything. We were involved in running the groups and that was important. We all had this sense of ownership, and it's hugely empowering. (Gay 003)

\section{Support at work}

Increasingly, there are policy directives for employers to help them recognize and support people at work in terms of mental health. The issues were highlighted by one participant:

I've an employer now who recognizes these things, and it's been amazing, like even working for them part time, I could access every single service if I needed it. They organized it, they were fantastic, and all on company expenses. (Gay 003)

\section{DISCUSSION}

The main directives in guiding mental health policy in Ireland, Vision for Change, are explicit and clear in their drive towards a recovery-orientated, consumer-led, rights-based mental health service (Department of Health and Children 2006; Mental Health Reform 2013). Furthermore, a recent review of mental health nursing highlighted the need for responsive, skilled, competent practitioners who value equality, respect for diversity, empowerment, and human rights (Health Service Executive 2012). However, many of the directives and recommendations contained in these documents have yet to be realized in terms of mental health service provision (Bracken et al. 2012). While some participants in the present study reported positive experiences, it has become more evident that current services are not in line with national policy. Participants indicated that they would like to see the existing service provision reviewed and changes made, in order to be more responsive to the needs of LGBT people. This included increasing access, providing knowledgeable and responsible practitioners, and allowing for the choice of a range of therapeutic approaches, including the provision of talking therapies that are accessible and affordable. Participants spoke of their hopes for 'responsive, seamless, and holistic services'. For some, long waiting lists and having to pay for health care were burdensome. Most people wanted a service where people were treated with dignity and respect, and they provided valid ideas for tackling stigma and discrimination, such as media campaigns to raise public awareness, aspects that lie at the heart of a recovery approach and form a fundamental part of a modern mental health-care system (Department of Health and Children 2006; Mental Health Commission 2008). Several participants wanted mental health practitioners to be better educated about LGBT issues, and suggested 'equality training' in the workplace. They spoke about creating good practice guidelines that would assist in the provision of the necessary services and treatments, and identified more work needed on 'silent carers' and significant others in terms of systematic support and psychoeducation. Some people recognized the effects of minority stress in young people and the risks associated with suicide (Meyer 2003). Opportunities were highlighted in educating young people about LGBT issues in schools.

\section{LIMITATIONS}

The present study provides important insights into the experiences of LGBT people in relation to mental health services. However, the researchers were unable to recruit LGBT people from a variety of ethnic backgrounds, older LGBT populations, and people staying in psychiatric 
hospitals or residential care facilities. Future research should include strategies to include these populations.

\section{CONCLUSION}

Mental health nurses are in a prime position to influence the development and delivery of services and therapeutic interventions that would be truly responsive to the needs of LGBT people. While appreciating resilient attributes, nurses can give LGBT people support in response to specific mental health concerns, such as depression and anxiety. Furthermore, there are distinct steps that nurses can take to ensure that their practice is more inclusive to the needs of LGBT people, such as appreciating the fears associated with coming out, homophobic bullying, violence, and harassment. Nurses can challenge antigay bias and adopt an LGBT-affirmative approach by using inclusive language, displaying LGBT information leaflets, and using signs that recognize diversity. Finally, current mental health policy directives should support the development of practice and education initiatives to demonstrate openness, respect, and understanding towards LGBT service users.

\section{ACKNOWLEDGEMENTS}

The authors would like to thank all of the people who kindly took part in the study, and to the research advisory group. They are also grateful for the financial support received from the Gay and Lesbian Equality Network and the Health Service Executive and to Trinity College Dublin for awarding a Postdoctoral Fellowship.

\section{REFERENCES}

Australian Government (2010). National Standards for Mental Health Services: National Mental Health Strategy. Canberra: Commonwealth of Australia.

Bracken, P., Thomas, P., Timimi, S. et al. (2012). Psychiatry beyond the current paradigm. The British Journal of Psychiatry, 201, 430-434.

Butler, S. S. (2004). Gay, lesbian, bisexual, and transgender (GLBT): The challenges and resilience of this marginalized group. Journal of Human Behavior in the Social Environment, 9 (4), 25-44.

Coleman, E., Bockting, W., Botzer, M. et al. (2011). Standards of care for the health of transsexual, transgender, and gender-nonconforming people, version 7. International Journal of Transgenderism, 13, 165-232.

Collins, E. \& Sheehan, B. (2004). Access to Health Services for Transsexual People. In: Equality Research Series. Dublin: The Equality Authority.
Department of Health (2013). Healthy Ireland: A Framework for Improved Health and Well-Being 2013-2025. Dublin: Department of Health.

Department of Health and Children (2006). A Vision for Change: Report of the Expert Group on Mental Health Policy. Dublin: Stationery Office.

Equality Authority (2002). Implementing Equality for Lesbians, Gays and Bisexuals. Dublin: Equality Authority.

Flanagan, S. M. \& Hancock, B. (2010). 'Reaching the hard to reach' - lessons learned from the VCS (voluntary and community sector): A qualitative study. BMC Health Services Research, 10, 92.

Government of Ireland (2003). Data Protection (Amendment) Act 2003. Dublin: Stationary Office.

Government of Scotland (2006). Rights, Relationships and Recovery: The Report of the National Review of Mental Health Nursing in Scotland. Edinburgh: Scottish Executive.

Grant, J. M. \& Mottet, L. A. (2011). Injustice at Every Turn: A Report of the National Transgender Survey. Washington, DC: National Gay and Lesbian Task Force and National Center for Transgender Equality.

Grossman, B. \& Hollibaugh, A. (2008). Resilience over the rainbow: Aging in lesbian, gay, bisexual and trans (LGBT) communities. The Gerontologist, 48 (3), 22.

Health Service Executive (2009). LGBT Health: Towards Meeting the Health Care Needs of Lesbian, Gay, Bisexual and Transgender People. Dublin: Health Service Executive.

Health Service Executive (2012). A Vision for Psychiatricl Mental Health Nursing: A Shared Journey for Mental Health Care. Dublin: Health Service Executive.

Heck, J. E., Sell, R. L. \& Gorin, S. S. (2006). Health care access among individuals involved in same-sex relationships. American Journal of Public Health, 96 (6), 1111-1118.

Kandirikirira, N. \& Botfield, J. (2004). Getting It Right: LGBT Research Guidelines. Glasgow: The Inclusion Project.

Kelleher, C. (2009). Minority stress and health: Implications for lesbian, gay, bisexual, transgender, and questioning (LGBTQ) young people. Counseling Psychology Quarterly, 22 (4), 373-379.

King, M., Semlyen, J., Tai, S. S. et al. (2008). A systematic review of mental disorder, suicide, and deliberate self harm in lesbian, gay and bisexual people. BMC Psychiatry, 8, $1-17$.

Kuyper, L. \& Fokkema, T. (2011). Minority stress and mental health among Dutch LGBs: Examination of differences between sex and sexual orientation. Journal of Counseling Psychology, 58 (2), 222-233.

Lincoln, Y. \& Guba, E. (1985). Naturalistic Inquiry. Beverly Hills, CA: Sage Publications.

Makadon, H. J. (2011). Ending LGBT invisibility in health care: The first step in ensuring equitable care. Cleveland Clinic Journal of Medicine, 78 (4), 220-224. 
Mayock, P., Bryan, A., Carr, N. \& Kitching, C. (2009). Supporting LGBT Lives: A Study of the Mental Health and WellBeing of Lesbian, Gay, Bisexual and Transgender People. Dublin: Gay and Lesbian Equality Network (GLEN) and BeLonG To Youth Service.

McCann, E. \& Sharek, D. (2013). A survey of lesbian, gay, bisexual and transgender people's experiences of mental health services in Ireland. International Journal of Mental Health Nursing, 23, 118-127.

McCann, E., Sharek, D., Higgins, A., Glacken, M. \& Sheerin, F. (2013). Older people who are LGBT: Mental health issues. Aging and Mental Health, 17 (3), 358-365.

McNeil, J., Bailey, L., Ellis, S., Morton, J. \& Regan, M. (2012). Trans Mental Health and Emotional Wellbeing Study 2012. Edinburgh: Equality Network.

Mental Health Commission (2008). A Recovery Approach within the Irish Mental Health Services. A Framework for Development. Dublin: Mental Health Commission.

Mental Health Reform (2013). Recovery: What You Should Expect from A Good Mental Health Service. Dublin: Mental Health Reform.

Meyer, I. H. (1995). Minority stress and mental health in gay men. Journal of Health and Social Behavior, 36 (1), 38-56.

Meyer, I. H. (2003). Prejudice, social stress, and mental health in lesbian, gay, and bisexual populations: Conceptual issues and research evidence. Psychological Bulletin, 129 (5), 674697.
National Gay and Lesbian Federation (2009). Burning Issues. Dublin: National Gay and Lesbian Federation.

Newcomb, M. E. \& Mustanski, B. (2010). Internalized homophobia and internalizing mental health problems. A meta-analytic review. Clinical Psychology Review, 30 (8), 1019-1029.

Pachankis, J. E. \& Goldfried, M. R. (2004). Clinical issues in working with gay, lesbian, and bisexual clients. Psychotherapy: Theory, Research, Practice and Training, 41, 227246.

Phillips, J. \& Marks, G. (2007). Ageing lesbians: Marginalising discourses and social exclusion in the aged care industry. Australian Family Physician, 37 (8), 678-680.

QSR International (2008). NVivo Qualitative Analysis Software, Version 8. Cheshire: QSR International.

Shankle, M. D., Maxwell, C. A., Katzman, E. S. \& Landers, S. (2003). An invisible population: Older lesbian, gay, bisexual and transgender individuals. Clinical Research and Regulatory Affairs, 20 (2), 159-182.

Transgender Equality Network Ireland (2013). Speaking from the Margins: Trans Mental Health and Wellbeing in Ireland. Dublin: TENI.

World Health Organization (2009). Mental Health, Resilience and Inequalities. Copenhagen: WHO Regional Office for Europe. 